\title{
Erratum to: Long-Term Health and Psychosocial Status of Youth who Received Substance Abuse Treatment in Adolescence
}

\author{
Karen Leslie $^{1}$ - Stephanie Jeanneret Manning ${ }^{1}$ • \\ Catherine Maser $^{1}$ - Deirdre Snelgrove ${ }^{2}$. \\ Tiffany Thornton ${ }^{3}$ - Andrea Wills ${ }^{3}$ - Bruna Brands ${ }^{1,3}$
}

Published online: 20 October 2015

(C) Springer Science+Business Media New York 2015

\section{Erratum to: Int J Ment Health Addiction \\ DOI 10.1007/s11469-015-9585-7}

Please note that the name of coauthor Stephanie Jeanneret Manning appeared incorrectly as "Stephanie Jeanneret-Manning Manning" in the pdf and html versions of this article as originally published Online First.

The online version of the original article can be found at http://dx.doi.org/10.1007/s11469-015-9585-7.

\section{Karen Leslie}

karen.leslie@sickkids.ca

1 University of Toronto, Toronto, ON, Canada

2 College of Family Physicians of Canada, Mississauga, ON, Canada

3 Health Canada, Ottawa, ON, Canada 